\title{
A Young Lady with Hedache and Skin Laxity- A Case Report
}

\author{
MD. ROBED AMIN,${ }^{1}$ FARUQUE AHMED,${ }^{2}$ FARIA MAHBUBA, ${ }^{3}$ AHMED RIYADH HOSSAIN,${ }^{4}$ \\ MD. MOHSIN, ${ }^{5}$ MD. AZIZUL KAHHAR ${ }^{6}$
}

\begin{abstract}
:
Pseudoxanthomaelasticum (PXE) is amendelian autosomal recessive disorder characterised pathologically by elastic fibre mineralisation and clinically by angioid streaks, yellow skin papules and cardiovascular involvement. A case of PXE which manifested with cutaneous features along with nephrocalcinosis was diagnosed recently in Medicine department of Dhaka Medical College Hospital which is a rarity of its own.
\end{abstract}

Key words: Headache, Skin Laxity, Pseudoxanthomaelasticum

\section{Introduction:}

Pseudoxanthomaelasticum (PXE) is a mendelian autosomal recessive disorder which is characterized by ectopic mineralization of connective tissues in a variety of organs, including the skin, the eyes, and the cardiovascular system, with considerable morbidity and mortality. ${ }^{1}$ pseudoxanthomaelasticum most commonly involves the elastic fibers of the mid and deep reticular dermis of skin, the Bruch membrane of the eye, and the blood vessels. The disease's manifestations are primarily due to an underlying metabolic disorder. ${ }^{2}$ Finally, the disease has been suggested to be more severe in women, and the female-male ratio of affected individuals has been reported to be approximately 2:1. ${ }^{1}$ We here by present a case of PXE which manifested with cutaneous features along with nephrocalcinosis. Such a finding has rarely been reported earlier in literature.

\section{Case report:}

Mrs. N. Y, 26-year-old lady from Dhamrai got herself admitted in DMCH with complaints of headache for two years and skin laxity for five years. She is not known to be diabetic, hypertensive or asthmatic. Her headache started at occiput, severe in intensity, throbbing in nature, non radiating but

1. Associate Professor, Dept. of Medicine, Dhaka Medical College\& Hospital.

2. Registrar, Dept. of Medicine, Dhaka Medical College\& Hospital.

3. Honorary Medical Officer, Dept. of Medicine, Dhaka Medical College \& Hospital.

4. Assistant Registrar, Dept. of Medicine, Dhaka Medical College\& Hospital.

5. Medical Officer, Dept. of Medicine, Dhaka Medical College\& Hospital.

6. Professor of Medicine, Dept. of Medicine, Dhaka Medical College\& Hospital.

Correspondence : Dr. Md. Robed Amin, Associate Professor of Medicine, Department of Medicine, Dhaka Medical College, Bangladesh.Apt-C-2, House no-76, Road-5,Block-F, Banani, Dhaka, Bangladesh. e.mail: robedamin@yahoo.com. associated with photophobia, nausea and occasional episodes of vomiting. Headache was aggravated by exposure to sun and relieved by taking medication like Paracetamol and rest in dark, there was no diurnal variation of headache. Initially it occurred with a frequency of 1-2 times per month and persist for one day with complete remission in between. Since $25^{\text {th }}$ march, 2011 her headache is severe and persistent starting at same location, throbbing in nature, has no radiation associated with nausea, but no vomiting and not relieved even by taking medication. There is no history of fever, convulsion, visual disturbance or loss of consciousness. There was no ENT ailments during any period of illness. It is not aggravated by coughing, sneezing, bending of head and neck or straining. Her skin complaints started five years back with multiple, confluent papules at the lateral surface of the neck which gradually involved whole neck that was not associated with itching, scaling or pain. In course of time laxity of skin developed in the neck. There was no scarring, hyperkeratosis or cicatrisation, no discharge or bleeding. Gradually her groin was involved. Onquery she stated that she has been suffering from acne since last 10 years which used to regress by conservative management. Patient gave no history of chest pain, abdominal pain, pain on limbs, visual disturbance urinary complaints or any bleeding suggestive of GI hemorrhage. None of her family member is affected and she is not a issue of consanguineous marriage. On query patient complained of sleep disturbance, loss of appetite and constipation for last onemonth. She was diagnosed as a case of PLID in DMCH in august, 2009 that is improved with conservative management. Her menstrual history is normal. She was married in 2004 and divorced in 2006.

On examination - She is depressed, pulse- 80 beats $/ \mathrm{min}$, BP100/60 mm of $\mathrm{Hg}$ temperature- $98^{0} \mathrm{~F}$ papular skin lesions at neck especially in lateral surface and back of the neck, face, mid chest and groin bilaterally. Characteristics: In the neck and groin there is Yellowish papular lesion and indurated 
plaques with transverse creases with plucked chicken appearance of the skin,yellow and red papular lesion with erythema in face, no comedone. In mid chest yellowish papular lesion, no transverse crease, no laxity of skin, no discharge and no tenderness.

Examination of the cardiovascularsystem there is no murmur and all peripheral pulses are present and in normal volume. Opthalmascopy is normal. Laboratory investigations showed Hb-13 gm/dl, ESR-16mm in $1^{\text {st }} \mathrm{hr}$, WBC 7640/cumm, neutrophil-58.3\%, lymphocyte-35.7\%, monocyte-4.2\% eosinophil-1.7\%, basophil 0.1\% . PBF- RBC normocytic normochromic, WBC mature with normal distribution. Platelets - adequate. S. creatinine- $1.27 \mathrm{gm} / \mathrm{dl} \mathrm{S}$. fasting lipid profile-S.cholesterol-171mg/dl, HDL -41mg/dl LDL$112 \mathrm{mg} / \mathrm{dl}$ TG-90mg/dl Chest Xray (P-A) - Normal, ECG-
Normal , Echo- normal, CT scan of brain - Lt sided old cerebral infarct, MRI of brain-Encephalomalacic changes in Lt parietal region, urine routine microscopic examination revealed- colour-straw, sugar-nil, phosphate- nil Pus cell-1-2/HPF, RBC-1-2/HPF, Casts \& crystals -Absent. USG of whole abdomen- suggestive of nephrocalcinosis with normal other finding. Skin biopsy revealed that the reticular dermis reveals numerous elastic fibres with intervening calcification. The epidermis is unremarkable. The elastic fibres were swollen, clumped and stained basophilic with haematoxylin and eosin (H\&E) (Fig. 2a). Von Kossa stain confirmed calcification of elastic fibres (Fig. 2b).So, our final diagnosis was PseudoxanthomaElasticum with Bilateral Nephrocalcinosis with Encephalomalacia with Chronic Tension Headache.

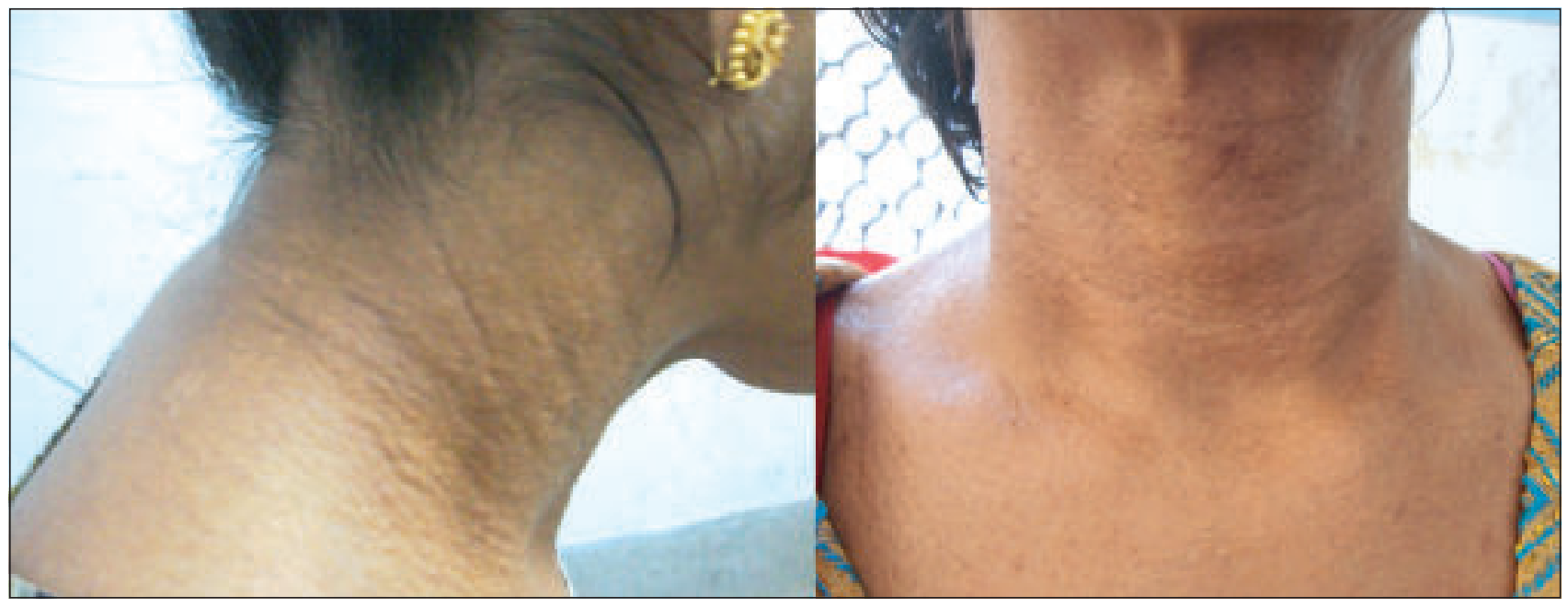

Fig: 1(a \& b): Yellowish papular lesion and indurated plaques with transverse creases in neck

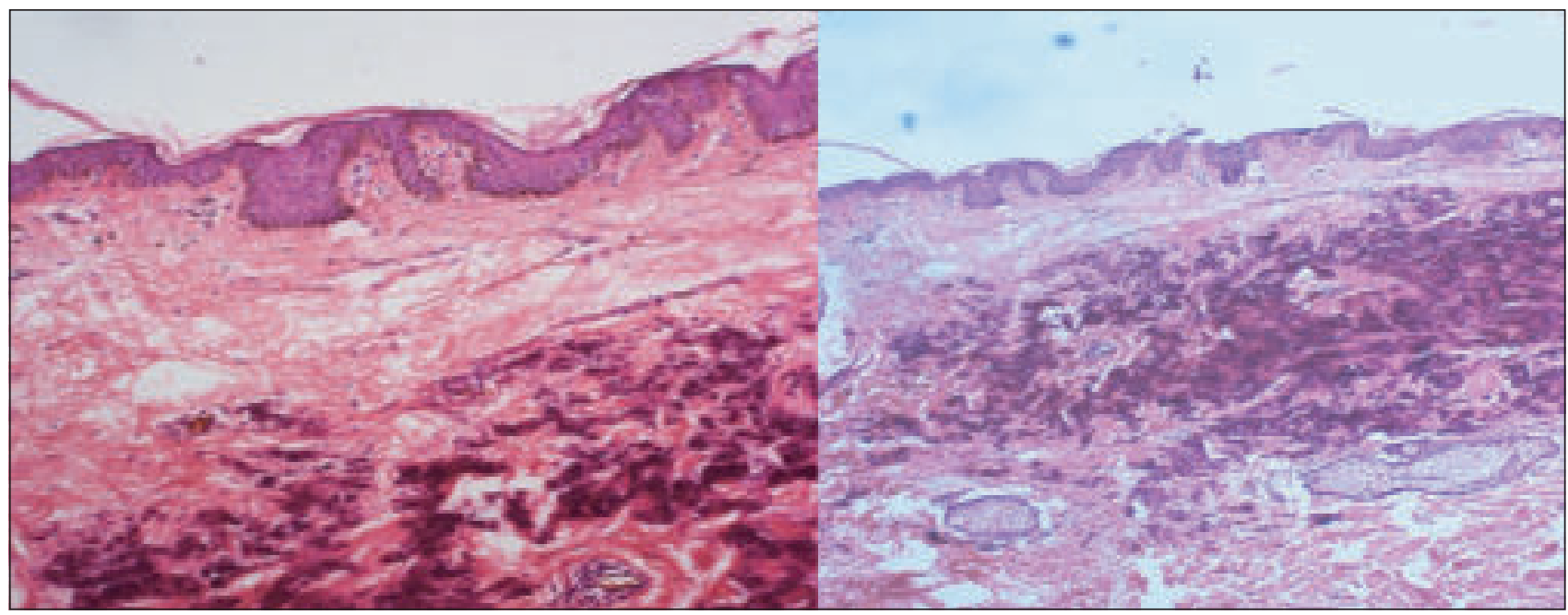

Fig 2(a \&b): Photomicrographs demonstrating calcified elastic fibres with (a) $H$ \& E stain and (b) von Kossa stain 


\section{Discussion}

Pseudoxanthomaelasticum (PXE) is a rare autosomal recessive disorder. $\mathrm{PXE}$ is now known to result from mutations in the $A B C C 6$ gene. ${ }^{3}$ This gene encodes multidrug resistance-associated protein 6 (MRP6), a putative transmembrane transporter, expressed primarily in the liver, to a lesser extent in proximal tubules of kidneys, and at very low levels, if at all, in tissues affected in PXE. It is characterised pathologically by elastic fibre mineralisation and clinically by angioidstreaks, yellow skin papules and cardiovascular involvement. ${ }^{2,3}$ Actually all findings are due to disordered metabolism and excess calcium accumulation.

Specifically, two localized cutaneous diseases that bear morphological, histopathological and ultrastructural resemblance to PXE have been recognized: (1) acquired PXE with skin lesions secondary to exogenous exposure to calcium-containing salts; and (2) localized acquired cutaneous PXE, a condition limited to the abdominal area, often with periumbilical and perforating lesions. ${ }^{1}$ In these conditions, no evidence of systemic involvement, characteristic of classic PXE, was noted.In addition, PXElike skin lesions have been reported in association with longterm treatment with penicillamine as well as within the spectrum of cutaneous findings in tryptophan-induced eosinophilia-myalgia syndrome. Among genetic diseases, PXE-like findings are present in a number of patients with thalassemia, and in fact, in a series of 100 patients with thalassemia from Greece, as many as one-quarter of patients had PXE-like skin lesions and/or angioid streaks . 4,5

The cutaneous manifestations of pseudoxanthomaelasticum are highly characteristic. The lesions usually develop in childhood or early adolescence; however, occasionally, they first appear in late adulthood, ${ }^{6,7,8}$ Small, yellow papules of 1$5 \mathrm{~mm}$ in diameter. ${ }^{9}$ The skin takes on a plucked chicken, Moroccan leather, or cobblestone appearance. Typically, these changes are first noted on the lateral part of the neck and later involve the antecubital fossae; the axillae; the popliteal spaces; the inguinal and periumbilical areas; the oral mucosa involving the lower lip, cheek, and palate; and the vaginal and rectal mucosae. ${ }^{10}$ As the disease progresses, the skin of the neck, the axillae, and the groin may become soft, lax, and wrinkled, hanging in folds. The extent of these changes is usually limited, but generalized cutis laxa-like pseudoxanthomaelasticum has also been reported. ${ }^{11}$ The cutaneous lesions of pseudoxanthomaelasticum usually remain unchanged throughout life, and are generally symmetrically distributed. In our patient the site of involvement of skin lesion was predominantly neck. She has typical skin lesion with plucked chicken skin in neck, upper chest, upper back and groin.

There are some case reports of stroke in pseudoxanthoma patient. Usually bilateral angiod streak found in pseudoxanthomaelasticum. In our patientthere is evidence of left cerebral ischemia in MRI. There is also encephalomalacia of left parietal region in same film which is an unique finding. She presented with headache in our hospital but it is non consistent with the MRI findings. The headachewas non specific, no red sign was observed and it responded with anxiolytic and encephalomalaciais disproportionate to symptoms. In PXE ocular involvement with retinal haemorrhages leads to the progressive loss of central vision. Peripheral vision is always spared. Ophthalmic examination is essential to detect early signs of retinopathy, angioid streaks, and retinal haemorrhages. Laser treatment may spare vision. In our patient ophthalmoscopy is normal.

Various cases of nephrocalcinosis along with other features of PXE have been reported. Visceral calcification in the form of pulmonary, renal, pancreatic and splenic calcification has been rarely reported in PXE. ${ }^{12}$ Various cases of nephrocalcinosis along with other features of PXE have been reported earlier though diffuse renal calcification has been mentioned only in a report of two cases. ${ }^{13,14}$ Multiple highly reflective foci in the corticomedullary junction have been reported earlier. ${ }^{15,16,17}$ The presentation of skin change, renal calcification and encephalomelacia in a same patient made our case unique as such combination has not been very common in Psedoxanthomaelasticum around the world.

\section{Conflict of interest: None.}

\section{References:}

1. Neldner KH. Pseudoxanthomaelasticum. Int J Dermatol. Mar 1988; 27(2): 98-100.

2. Bercovitch L, Terry P. Pseudoxanthomaelasticum 2004. J Am Acad Dermatol. Jul 2004; 51(1): 13-4.

3. Miksch S, Lumsden A, Guenther UP, Foernzler D, ChristenZach S, Daugherty C et al. Molecular genetics of pseudoxanthomaelasticum: type and frequency of mutations in ABCC6. Hum Mutat 2005; 26: 235-48.

4. Aessopos A, Savvides P, Stamatelos G, Rombos I, Tassiopoulos T, Karagiorga $\mathrm{M}$ et al. Pseudoxanthomaelasticum-like skin lesions and angioid streaks in -thalassemia. Am J Hematol1992; 41:159-164.

5. Hamlin N, Beck K, Bacchelli B, Cianciulli P, PasqualiRonchetti I, Le Saux O. Acquired pseudoxanthomaelasticumlike syndrome in -thalassaemia patients. Br J Haematol 2003; 122: 852-854.

6. Bercovitch L, Terry P. Pseudoxanthomaelasticum 2004. J Am Acad Dermatol 2004; 51(1): 13-4. 
7. ShererDW, Bercovitch L, Lebwohl M. Pseudoxanthomaelasticum: significance of limited phenotypic expression in parents of affected offspring. J Am Acad Dermatol 2001; 44(3): 534-7.

8. Li TH, Tseng CR, Hsiao GH, Chiu HC. An unusual cutaneous manifestation of pseudoxanthomaelasticum mimicking reticulate pigmentary disorders. Br J Dermatol 1996; 134(6): 1157-9.

9. McDonald HR, Schatz H, Aaberg TM. Reticular-like pigmentary patterns in pseudoxanthomaelasticum. Ophthalmology 1988; 95(3): 306-11.

10. Uenishi $T$, Uchiyama $M$, Sugiura $H$, Danno $K$. Pseudoxanthomaelasticum with generalized cutaneous laxity. Arch Dermatol1997; 133(5): 664-6.

11. Spinzi G, Strocchi E, Imperiali G, Sangiovanni A, Terruzzi V, Minoli G. Pseudoxanthomaelasticum: a rare cause of gastrointestinal bleeding. Am J Gastroenterol 1996; 91(8): 1631-4.
12. Suarez MJ, Garcia JB, Orense M, Raimunde E, Lopez MV, Fernandez O. Sonographic aspects of pseudo xanthomaelasticum. Paediatr Radiol 1991; 21: 538-9.

13. Makharia GK, Thapa BR, Poddar U. Pseudoxanthomaelasticum: A rare cause of recurrent gastrointestinal bleeding in a child. Indian J Gastroenterol 2004; 23: 231-2.

14. Chraïbi R, Ismaili N, Belgnaoui F. Pseudoxanthomaelasticum and nephrocalcinosis. Ann Dermatol Venereol 2007; 134: 764-6.

15. Ortiz Gorraiz MA, Casares Arias A, Tallada Buñuel M, Vicente Prados FJ, HonrubiaVílchez B, Fernández Sánchez A. Urologic findings in pseudoxanthomaelasticum: report one case. Actas Urol Esp 2005; 29: 96-9.

16. Crespi G, Derchi LE, Safûoti S. Sonographic detection of renal changes in pseudoxanthomaelasticum. Urol Radiol 1992; 13: 223-5.

17. Lt Col B Vasudevan, LtCol Shijith KP, Lt Col A Bahal, Col V Raghav, VSM. PseudoxanthomaElasticum with Renal Cortical Calcification. MJAFI 2010; 66: 272-274. 